\title{
Influence of zinc substitution on structural, elastic, magnetic and optical properties of cobalt chromium ferrites
}

\author{
Talat Zeeshan ${ }^{1, *}$, Safia Anjum, Salma Waseem ${ }^{1}$, Farzana Majid ${ }^{2}$, Muhammad Danish Ali $^{2}$, Ammara \\ Aslam $^{2}$ \\ ${ }^{1}$ Department of Physics, Lahore College for Women University, Lahore, Pakistan \\ ${ }^{2}$ Department of Physics, Punjab University Lahore, Lahore, Pakistan
}

\begin{abstract}
The polycrystalline $\mathrm{Co}_{1-\mathrm{x}} \mathrm{Zn}_{\mathrm{x}} \mathrm{Cr}_{0.5} \mathrm{Fe}_{1.5} \mathrm{O}_{4}$ series with $(\mathrm{x}=0,0.2,0.4,0.6,0.8,1.0)$ has been synthesized by conventional ceramic rout method. The structural and elastic properties have been investigated by X-ray diffractometer and Fourier transform spectroscopy. Both XRD and FTIR confirm the formation of single phase cubic spinel ferrites. The cationic distribution for all samples has been proposed. The lattice parameter, X-ray density, hoping length, bond length, and packing factors-in accompaniment with variations in the zinc concentration-have been studied. The IR band position has been explained by the cations involved in the structure. The elastic moduli such as Young's modulus, bulk modulus, rigidity modulus and Poison's ratio have bee calculated using force constants. Scanning electron microscope (SEM) observation conveys information about the agglomeration of particles. The hysteresis curve obtained from vibrating sample magneto meter (VSM) conveys information about the soft nature of prepared compositions. The saturation magnetization decreases with addition of zinc ions and coercivity is almost zero. An increase in band gap energy has been observed with addition of zinc by Ultraviolet Visible Spectroscopy (UV-VIS), which is due to small crystallite size.
\end{abstract}

Keywords: cationic distribution, force constant, dielectric constant, aglomeration

\section{Introduction}

Spinel ferrites are extensively used in numerous applications, including magnetic fluids, magnetic cores, information storage, ferrofluids, magnetic resonance imaging, sensors and electronic devices $[1,2]$. Among several ferrites, cobalt ferrites and zinc ferrites have been extensively studied because they show the properties of typically inverse spinel and normal ferrites, respectively [3]. The bulk zinc ferrite is antiferromagnetic below Neel temperature $\left(\mathrm{T}_{\mathrm{N}}=10 \mathrm{~K}\right)$ and becomes super-paramagnetic or ferromagnetic when particle size decreases to nanoscale in $\mathrm{Zn}^{2+}$ ferrites. Thus, mixed Co- $\mathrm{Zn}$ ferrites have significant attention owing their interesting and different properties. Arulmurugan at al. mentioned that the substitution of $\mathrm{Co}^{2+}$ with $\mathrm{Zn}^{2+}$ leads to improvement in the magnetic properties of nano crystalline ferrites [29]. Islam et al. reported that with increasing the zinc concentration

*E-mail: talats@hotmail.com the saturation magnetization decreases in cobalt zinc ferrites prepared by ceramic rout method [3]. It is also observed that the magnetic quantities like $H_{C}, M_{S}$, and $M_{r}$ decrease with enhancement of $\mathrm{Zn}^{2+}$ concentration. References in the literature observe decreasing behavior in particle size and saturation magnetization in $\mathrm{Co}-\mathrm{Zn}$ ferrites. The current work deals with fabrication $\mathrm{Co}_{1-\mathrm{x}} \mathrm{Zn}_{\mathrm{x}} \mathrm{Cr}_{0.5} \mathrm{Fe}_{1.5} \mathrm{O}_{4}$ $(\mathrm{x}=0,0.2,0.4,0.8,1.0)$ ferrite via solid-state reaction method. This work is an effort to examine the structural, elastic, magnetic, and optical properties of zinc doped cobalt ferrites.

\section{Experimental details}

The solid-state reaction method was used to fabricate the $\mathrm{Co}_{1-\mathrm{x}} \mathrm{Zn}_{\mathrm{x}} \mathrm{Cr}_{0.5} \mathrm{Fe}_{1.5} \mathrm{O}_{4}$ ferrites. The preparation of samples has been done by high purity reagents' mixing such as zinc oxide, chromium oxide, cobalt oxide, and iron oxide in precise stoichiometric ratio. The grinding of mixed powder was done for few hours by using motor and pes- 
tle. Next, the powder was calcified at $1100{ }^{\circ} \mathrm{C}$ for $6 \mathrm{~h}$ in a furnace and then gradually cooled down to room temperature inside the furnace. Finally, the powder samples were re-ground to get fine powder for characterizations.

\section{Characterization techniques}

The characterization of all prepared samples was done by X-ray diffractrometer (X'Pert PRO MPD) using $\mathrm{Cu} K \alpha 1$ radiation $(\lambda=1.54056 \AA)$, Fourier transform infrared spectroscopy (MIDAC 2000 USA, background subtraction, scan range 400-4500, scanning electron microscope (JEOL JSM-6480 LV), vibrating sample magnetometer, and ultraviolet visible spectroscopy $(\mathrm{UV}=2800$ model, Hitatchi Japan, wavelength $=300-900 \mathrm{~nm}$, respectively.

\subsection{X-ray diffraction}

Figure 1 shows the XRD pattern of synthesized $\mathrm{Co}_{1-\mathrm{x}} \mathrm{Zn}_{\mathrm{x}} \mathrm{Cr}_{0.5} \mathrm{Fe}_{2} \mathrm{O}_{4}$ ( $\mathrm{x}=0,0.2,0.4,0.8$, 1.0) ferrite. All the perceived peaks are matched with JCPD cards (22-1086 and 89-1012) and could be allocated to the reflection plane of (111), (220), (311), (222), (400), (422), (511), (440), which indorses the formation of single cubic spinel structure with no extra phases.

The lattice parameters of the prepared system have been assessed using the classical equation [4]:

$$
a=d\left[\left(h^{2}+k^{2}+l^{2}\right)\right]^{1 / 2}
$$

The crystallite sizes of these ferrites have been intended from line broadening (311) plane using Debye Scherrer formula [5]:

$$
D_{\mathrm{hkl}}=0.9 \lambda / \beta \cos \theta
$$

where $D_{\mathrm{hkl}}$ is crystallite size, $\lambda$ is wavelength of the radiation, $\beta$ is full width at half maximum of corresponding peaks and $\theta$ is angular position.

$\mathrm{X}$-ray densities for whole composition of ferrites have been calculated by the relation [6]:

$$
\rho=8 \mathrm{M} / \mathrm{Na}^{3}
$$

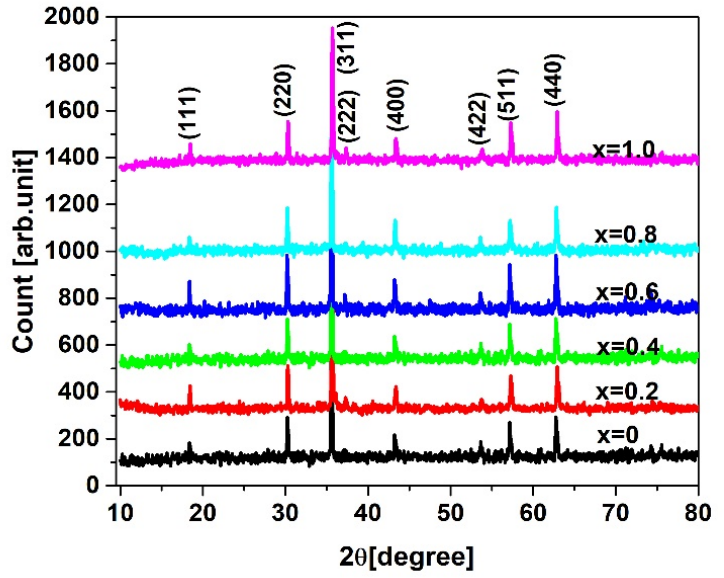

(A)

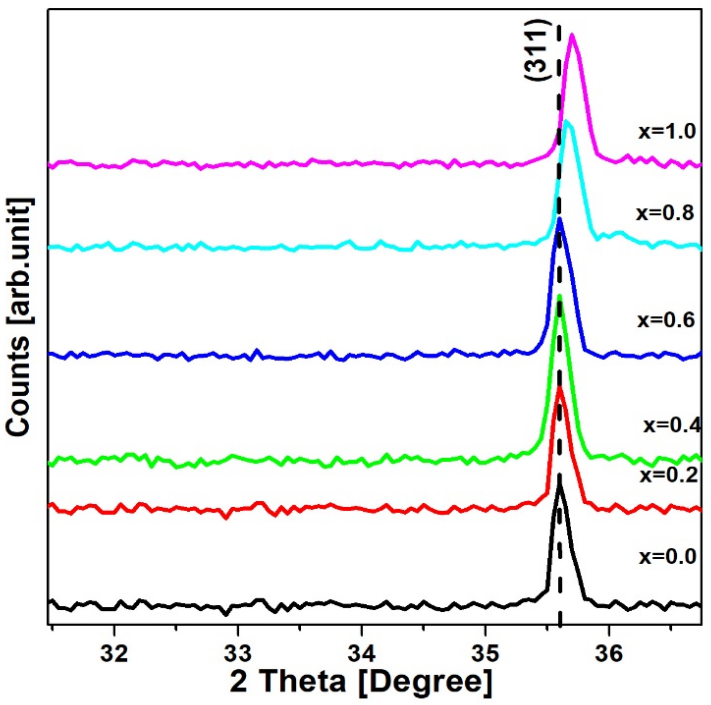

(B)

Fig. 1. (A) X-Ray diffraction pattern of $\mathrm{Zn}_{\mathrm{x}} \mathrm{Co}_{1-\mathrm{x}} \mathrm{Cr}_{0.5} \mathrm{Fe}_{1.5} \mathrm{O}_{4}$. (B) X-Ray diffraction patterns of $\mathrm{Co}_{1-\mathrm{x}} \mathrm{Zn}_{\mathrm{x}} \mathrm{Cr}_{0.5} \mathrm{Fe}_{1.5} \mathrm{O}_{4}$.

where $\mathrm{M}=$ molecular weight of the ferrite sample, $\mathrm{N}=$ Avogadro's numbers and "a" = lattice constant.

The bulk density of prepared ferrites samples has been calculated using following relation:

$$
d_{\mathrm{x}}=\mathrm{M} / \pi r^{2} t
$$

where $\mathrm{M}=$ the molecular weight, " $r "=$ radius 
and $" t "=$ thickness of the prepared pallets. All the extracted parameters have been listed in Table 1.

The variation of lattice parameter and X-ray density with zinc contents are shown in Figure 2. It is observed from the said figure that the lattice parameter increases with increasing the zinc ion concentration. The deviation in lattice constant is due to the dissimilarity in ionic radii of substituted and replaced ions. Normally, the preference of zinc is to reside on the tetrahedral site, while the preferential site of cobalt ions are octahedral site; however, here-due to a large difference in ionic radii $\mathrm{Zn}$ $(0.82 \AA)$ Co $(0.78 \AA)-$ it travels toward the octahedral site and substitutes the cobalt ion. As a result, a bigger expansion in the crystal lattice is observed; so, an increase in lattice parameters is expected.

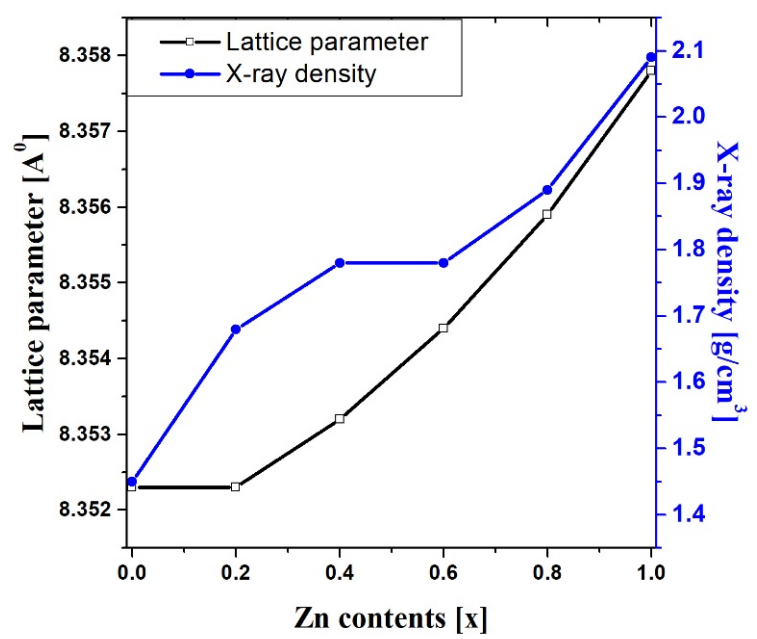

Fig. 2. Variation of lattice parameter and X-ray density with zinc contents.

It has been clearly seen from Figure 2 that X-ray density increases with increasing the zinc concentration. X-ray density is influenced by the molecular weight and lattice constant. The atomic weight of zinc atom $(65.38 \mathrm{amu})$ is larger than the cobalt (58.933 amu); so, the molecular weights increase. On the other hand, cell volume also increases, as observed in XRD portion [7, 8]; however, the proportion of increasing unit cell volume does not show the significant effect in comparison of molecular weight; thus, an increase in X-ray density has been witnessed. Similarly, the values of bulk den- sity listed in Table 1 are also showing the same behavior.

The crystallite size is perceived to decrease with increasing zinc content. This trend may be due to larger ionic radius of zinc in comparison of cobalt, which produces the lattice strains and disorder in the lattice structure that hinders the growth of grains and causes the reduction in size of particles. The decrement in particle size and increase in lattice strains leads to slight peak broadening, which is shown in Figure 1B.

Hopping lengths at A-site $\left(\mathrm{L}_{\mathrm{A}}\right)$ and B-site $\left(\mathrm{L}_{\mathrm{B}}\right)$ can be calculated by the following relation, and their values have been entered in Table 5 .

$$
\begin{aligned}
& \mathrm{L}_{\mathrm{A}}=\mathrm{a}\left[(3)^{1 / 2} / 4\right] \\
& \mathrm{L}_{\mathrm{B}}=\mathrm{a}\left[(2)^{1 / 2} / 4\right]
\end{aligned}
$$

It has been detected that the hopping lengths " $\mathrm{L}_{\mathrm{A}}$ " and " $\mathrm{L}_{\mathrm{B}}$ " between magnetic ions at site $\mathrm{A}$ and $B$ increase with enhancement in the zinc concentration. It is noted from the above equations that $\mathrm{L}_{\mathrm{A}}$ and $L_{B}$ show the same trend as of lattice constant; this may be ascribed to the enlargement of unit cell caused by doping of relatively larger zinc ions instead of smaller cobalt ions.

Using formulae given below, the mean ionic radii $r_{A}$ and $r_{B}$ corresponding to tetrahedral and octahedral sites have been intended and their values are listed in Table $2[9,10]$ :

$$
\begin{gathered}
\mathrm{r}_{\mathrm{A}}=\left(\mathrm{u}-\frac{1}{4}\right) \mathrm{a} \sqrt{3}-\mathrm{R}_{\mathrm{o}} \\
\mathrm{r}_{\mathrm{B}}=\left(\frac{5}{8}-\mathrm{u}\right) \mathrm{a}-\mathrm{R}_{\mathrm{o}}
\end{gathered}
$$

where " $\mathrm{u}$ " is the oxygen positional parameter and its value is $0.375 \AA$.

The XRD data is also useful to calculate bond lengths $R_{A}$ and $R_{B}$ corresponding to tetrahedral and octahedral sites, using the following relations [11, 12]. 
Table 1. Different parameters obtained from XRD diffractograms.

\begin{tabular}{lllllll}
\hline $\begin{array}{l}\text { Zinc } \\
\text { contents }(\mathrm{x})\end{array}$ & $\begin{array}{l}\text { Lattice } \\
\text { parameter }(\AA)\end{array}$ & $\begin{array}{l}\text { Crystallite } \\
\text { size }(\mathrm{nm})\end{array}$ & $\begin{array}{l}\text { Particle } \\
\text { size }(\mathrm{nm})\end{array}$ & $\begin{array}{l}\text { Bulk density X-Ray density Energy Band } \\
\mathrm{d}\left(\mathrm{g} / \mathrm{cm}^{3}\right)\end{array}$ & $\begin{array}{l}\mathrm{r}\left(\mathrm{gm} / \mathrm{cm}^{3}\right) \\
\mathrm{gap}(\mathrm{eV})\end{array}$ \\
\hline \hline 0 & 8.3523 & 68.11 & 400 & 2.02 & 1.45 & 2.49 \\
0.2 & 8.3523 & 67.07 & 380 & 2.23 & 1.68 & 2.64 \\
0.4 & 8.3532 & 61.40 & 295 & 2.32 & 1.78 & 2.66 \\
0.6 & 8.3544 & 56.62 & 230 & 2.36 & 1.89 & 2.67 \\
0.8 & 8.3559 & 58.92 & 190 & 2.37 & 1.78 & 2.66 \\
1.0 & 8.3578 & 56.62 & 175 & 2. & 2.09 & 2.68 \\
\hline
\end{tabular}

Table 2. Structural parameters obtained from Eqs (7)(14).

\begin{tabular}{lllllllll}
\hline $\begin{array}{l}\text { Zinc Mean ionic } \\
\text { radii }(\mathrm{nm})\end{array}$ & \multicolumn{2}{l}{$\begin{array}{l}\text { USys- Bond } \\
\text { tem } \\
(\mathrm{nm})\end{array}$} & \multicolumn{2}{l}{$\begin{array}{l}\text { Packing } \\
\text { length }\end{array}$} & & \multicolumn{2}{l}{$\begin{array}{l}\text { Pactor } \\
\text { fnm }\end{array}$} \\
\hline $\mathrm{X}$ & $\mathrm{r}_{\mathrm{A}}$ & $\mathrm{r}_{\mathrm{B}}$ & & $\mathrm{R}_{\mathrm{A}}$ & $\mathrm{R}_{\mathrm{B}}$ & $\mathrm{P}_{\mathrm{A}}$ & $\mathrm{P}_{\mathrm{B}}$ \\
\hline \hline 0 & 3.6165 & 0.3828 & 0.482 & 3.723 & 1,932 & 0.990 & 4.467 \\
0.2 & 3.6166 & 0.3842 & 0.429 & 3.873 & 1.959 & 1.032 & 4.738 \\
0.4 & 3.6169 & 0.3842 & 0.418 & 3.989 & 1.975 & 1.064 & 4.780 \\
0.6 & 3.6174 & 0.3843 & 0.401 & 4.234 & 2.163 & 1.132 & 5.273 \\
0.8 & 3.6181 & 0.3843 & 0.393 & 4.392 & 2.195 & 1.176 & 5.3535 \\
1.0 & 3.6189 & 0.3844 & 0.331 & 4.751 & 2.229 & 1.275 & 5.473 \\
\hline
\end{tabular}

$$
\begin{gathered}
\mathrm{R}_{\mathrm{A}}=\mathrm{a} \sqrt{3}(\delta+1 / 8) \\
\mathrm{R}_{\mathrm{B}}=\mathrm{a}\left(3 \delta^{2}+1 / 16-\delta / 2\right)
\end{gathered}
$$

where $\delta=\mathrm{U}_{\text {system }}-\mathrm{U}_{\text {ideal }}$.

$\mathrm{U}_{\text {ideal }}=0.250$ and $\mathrm{U}_{\text {system }}=$ oxygen parameters $=\mathrm{U}=\left(\mathrm{u}_{1}+\mathrm{u}_{2}\right) / 2 ; \mathrm{u}_{1}$ and $\mathrm{u}_{2}$ are anion parameters that have been evaluated using given formula [12].

$$
\begin{gathered}
\mathrm{u}_{1}=\left(\mathrm{r}_{\mathrm{A}}+\mathrm{R}_{\mathrm{O}}\right) / \sqrt{3} \times \mathrm{a}_{\exp } \\
\mathrm{u}_{2}=\mathrm{U}_{1}-1 / 8
\end{gathered}
$$

The ionic packing coefficient $\mathrm{P}_{\mathrm{A}}$ and $\mathrm{P}_{\mathrm{B}}$ at tetrahedral and octahedral sites, respectively, have been estimated by the relation [13].

$$
\begin{aligned}
& \mathrm{P}_{\mathrm{A}}=\left(\mathrm{r}_{\mathrm{A}}-\mathrm{R}_{0}\right) / \mathrm{R}_{\mathrm{A}} \\
& \mathrm{P}_{\mathrm{B}}=\left(\mathrm{r}_{\mathrm{B}}-\mathrm{R}_{B}\right) / \mathrm{R}_{\mathrm{B}}
\end{aligned}
$$

where $R_{0}$ is the radius of oxygen ion (1.32 $\AA$ ). All these calculated parameters have been listed in Table 2.

It has been observed from Table 2 that mean ionic radii are increasing with increasing zinc ions. This is because it is well known that there is a connection between ionic radius and lattice parameter. So, it may be decided that zinc ions substitution plays a leading role in influencing the lattice parameters. This is because it is well known that there is a connection between ionic radius and lattice parameter. So, it may be decided that zinc ions substitution plays a leading role in influencing the lattice parameters.

It is clear from the table that bond lengths $R_{A}$ and $R_{B}$ are increasing with zinc concentration that is attributed to the increasing lattice constant with $x$. Moreover, the site radius $R_{B}$ has greater value than $R_{A}$ and this indicates that A-site contributes more to increase lattice parameters. It has been assessed from the table that packing factor $" \mathrm{P}_{\mathrm{A}}$ " is very small $(<1)$ at A-site, affirms to the shorter ionic distances and higher overlapping of the anion and cation orbits, proposing the presence of anion or cation vacancies at tetrahedral sites [14]. It is clear that $\mathrm{P}_{\mathrm{A}}$ and $\mathrm{P}_{\mathrm{B}}$ increase with increasing the zinc contents; furthermore, $\mathrm{P}_{\mathrm{A}}$ has very small values than $\mathrm{P}_{\mathrm{B}}$, which is the signal of enlarged domi- 
nance of the $\mathrm{Zn}^{2+}$ vacancies at A- sites, playing the double acceptor's role.

The inter-atomic distance between the cations " $\mathrm{M}_{\mathrm{e}}-\mathrm{M}_{\mathrm{e}}$ " are (b, c, d, e, and f) and the distance between cations and anions $\left(\mathrm{M}_{\mathrm{e}}-\mathrm{O}\right)$ are $(\mathrm{p}, \mathrm{q}, \mathrm{r}$, and $\mathrm{s}$ ); these have been calculated by using experimental lattice parameter values and oxygen parameter, by following relations and their values, which have been tabulated in Table 3 .

$$
\begin{array}{cc}
\mathrm{M}_{\mathrm{e}}-\mathrm{O} & \mathrm{M}_{\mathrm{e}}-\mathrm{M}_{\mathrm{e}} \\
\mathrm{p}=\mathrm{a}(1 / 2-\mathrm{u}) & \mathrm{b}=(\mathrm{a} / 4) \sqrt{2} \\
\mathrm{q}=\mathrm{a}(\mathrm{u}-1 / 8) \sqrt{3} & \mathrm{c}=(\mathrm{a} / 8) 11 \\
\mathrm{r}=\mathrm{a}(\mathrm{u}-1 / 8) \sqrt{11} & \mathrm{~d}=(\mathrm{a} / 4) \sqrt{3} \\
\mathrm{~s}=\mathrm{a} \sqrt{3}(\mathrm{u}+1 / 2) \sqrt{3} & \mathrm{e}=(3 \mathrm{a} / 8) \sqrt{3}
\end{array}
$$

Table 3. Inter atomic distance between the cations " $\mathrm{M}_{\mathrm{e}}-$ $\mathrm{M}_{\mathrm{e}}$ " and cations and anions "Me-O".

\begin{tabular}{lllllll}
\hline $\mathrm{x}$ & 0 & 0.2 & 0.4 & 0.6 & 0.8 & 1.0 \\
\hline \hline $\mathrm{b}$ & 3.6166 & 2.9530 & 2.9533 & 2.9537 & 2.9541 & 2.9549 \\
$\mathrm{c}$ & 3.4626 & 3.4627 & 3.4630 & 3.4635 & 3.4644 & 3.4649 \\
$\mathrm{~d}$ & 3.6165 & 3.6167 & 3.6170 & 3.6175 & 3.6182 & 3.6190 \\
$\mathrm{e}$ & 5.4249 & 5.4252 & 5.4255 & 5.4263 & 5.4273 & 5.4285 \\
$\mathrm{f}$ & 5.1147 & 5.1148 & 5.1152 & 5.1160 & 5.1169 & 5.1180 \\
$\mathrm{p}$ & 1.0440 & 1.0441 & 1.0442 & 1.0443 & 1.0444 & 1.0447 \\
$\mathrm{q}$ & 3.6165 & 3.6166 & 3.6169 & 3.6174 & 3.6181 & 3.6189 \\
$\mathrm{r}$ & 3.4578 & 3.4579 & 3.4583 & 3.4587 & 3.4593 & 3.4601 \\
$\mathrm{~s}$ & 4.2039 & 4.2040 & 4.2044 & 4.2050 & 4.2067 & 4.2071 \\
\hline
\end{tabular}

It has been revealed from the table that both cation-anion distance (p, q, r, s) and the distance between the cations (b, c, d, e, f) increase with increasing the zinc concentration, which is credited to the increase in mean ionic radii and bond lengths.

\subsubsection{Cationic distribution}

The estimated cationic distribution of prepared material and their preference sites have been shown in Table 4.

$\mathrm{Co}^{2+}$ and $\mathrm{Cr}^{3+}$ ions both prefer to occupy the octahedral site and iron is equally distributed between tetrahedral and octahedral site, whereas the
Table 4. Estimated cationic distribution from XRD.

\begin{tabular}{ll}
\hline $\mathrm{X}$ Tetrahedral site & Octahedral site \\
\hline \hline $0.0 \mathrm{Co}_{0.25} \mathrm{Fe}_{0.75}$ & $\mathrm{Co}_{0.75} \mathrm{Cr}_{0.5} \mathrm{Fe}_{0.75}$ \\
$0.2 \mathrm{Co}_{0.2} \mathrm{Zn}_{0.05} \mathrm{Fe}_{0.75}$ & $\mathrm{Co}_{0.6} \mathrm{Zn}_{0.15} \mathrm{Cr}_{0.5} \mathrm{Fe}_{0.75}$ \\
$0.4 \mathrm{Co}_{0.15} \mathrm{Zn}_{0.04} \mathrm{Cr}_{0.05} \mathrm{Fe}_{0.76} \mathrm{Co}_{0.45} \mathrm{Zn}_{0.36} \mathrm{Cr}_{0.45} \mathrm{Fe}_{0.74}$ \\
$0.6 \mathrm{Co}_{0.14} \mathrm{Zn}_{0.03} \mathrm{Cr}_{0.06} \mathrm{Fe}_{0.77} \mathrm{Co}_{0.26} \mathrm{Zn}_{0.57} \mathrm{Cr}_{0.44} \mathrm{Fe}_{0.73}$ \\
$0.8 \mathrm{Co}_{0.13} \mathrm{Zn}_{0.02} \mathrm{Cr}_{0.07} \mathrm{Fe}_{0.78} \mathrm{Co}_{0.07} \mathrm{Zn}_{0.78} \mathrm{Cr}_{0.43} \mathrm{Fe}_{0.72}$ \\
$1.0 \mathrm{Zn}_{0.01} \mathrm{Cr}_{0.08} \mathrm{Fe}_{0.0 .91}$ & $\mathrm{Zn}_{0.99} \mathrm{Cr}_{0.42} \mathrm{Fe}_{0.59}$ \\
\hline
\end{tabular}

$\mathrm{Zn}^{2+}$ ion also may have strong preference to occupy the tetrahedral site; however, in this situation, the ionic radii of $\mathrm{Zn}^{2+}$ is $0.84 \AA$ are unusually larger than ionic radii of $\mathrm{Co}^{2+}(0.78 \AA)$, which causes them to move most of the zinc ions toward the octahedral site and some of them toward tetrahedral site.

\subsection{FTIR analysis}

FTIR spectroscopy is a nondestructive method for accurate configuration of the ions or atoms in structure. The spectra have been recorded at room temperature to investigate the crystal structure of $\mathrm{Zn}_{\mathrm{x}} \mathrm{Co}_{1-\mathrm{x}} \mathrm{Cr}_{0.5} \mathrm{Fe}_{1.5} \mathrm{O}_{4}$, which is shown in Figure 3.

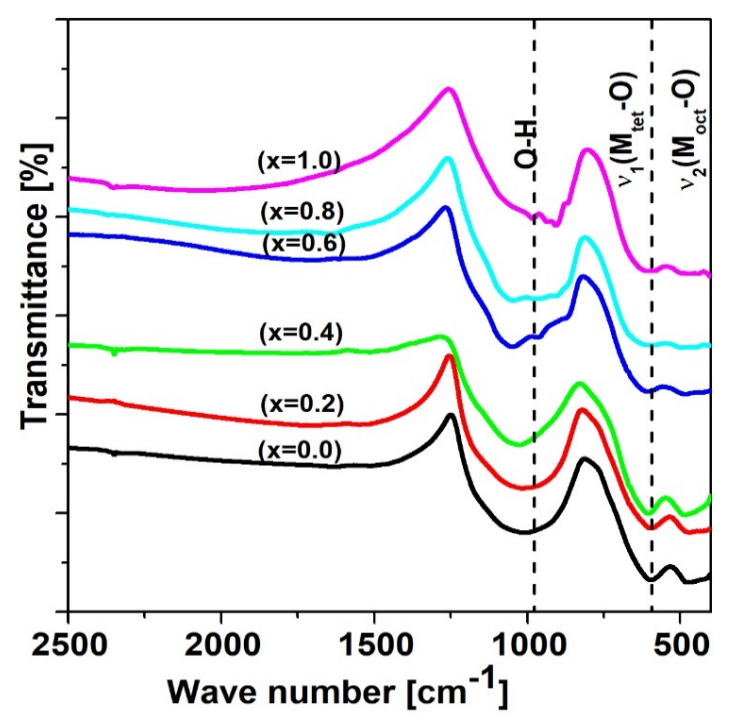

Fig. 3. FTIR spectra of $\mathrm{Co}_{1-\mathrm{x}} \mathrm{Zn}_{\mathrm{x}} \mathrm{Cr}_{0.5} \mathrm{Fe}_{1.5} \mathrm{O}_{4}$.

There are two main bands below $1000 \mathrm{~cm}^{-1}$ which are well recognized features of spinel ferrites. The lower frequency band $v_{2}$ has been observed at around $491-471 \mathrm{~cm}^{-1}$ corresponding to 
the octahedral metal vibration oxygen bond (M$\mathrm{O})$; the higher frequency bands are in the range of $612-604 \mathrm{~cm}^{-1}$, relate to the tetrahedral complexes, and their values are listed in Table 5. The broad bands centered around $1016-926 \mathrm{~cm}^{-1}$ correspond to $\mathrm{O}-\mathrm{H}$ group stretching vibration, which is due to water molecules in $(\mathrm{KBr})$ used during the preparation of pellets for FTIR analysis.

Table 5. FTIR analysis of $\mathrm{Co}_{1-\mathrm{x}} \mathrm{Zn}_{\mathrm{x}} \mathrm{Cr}_{0.5} \mathrm{Fe}_{2} \mathrm{O}_{4}$.

\begin{tabular}{lllllll}
\hline $\begin{array}{l}\mathrm{Zn} \\
(\mathrm{x})\end{array}$ & $\begin{array}{l}v_{2} \\
\left(\mathrm{~cm}^{-1}\right)\end{array}$ & $\begin{array}{l}v_{1} \\
\left(\mathrm{~cm}^{-1}\right)\end{array}$ & $\begin{array}{l}\mathrm{K}_{1} \\
(\mathrm{~N} / \mathrm{m})\end{array}$ & $\begin{array}{l}\mathrm{K}_{2} \\
(\mathrm{~N} / \mathrm{m})\end{array}$ & $\mathrm{L}_{\mathrm{A}}(\AA)$ & $\mathrm{L}_{\mathrm{B}}(\AA)$ \\
\hline \hline 0 & 487 & 612 & 16.12 & 14.62 & 3.7905 & 3.0950 \\
0.2 & 487 & 612 & 16.10 & 14.74 & 3.7909 & 3.0948 \\
0.4 & 483 & 604 & 15.73 & 14.21 & 3.7968 & 3.0997 \\
0.6 & 475 & 600 & 15.56 & 13.44 & 3.7977 & 3.1004 \\
0.8 & 471 & 597 & 15.49 & 13.32 & 3.7982 & 3.1009 \\
1.0 & 455 & 608 & 15.70 & 13.10 & 3.7994 & 3.1018 \\
\hline
\end{tabular}

The force constants $\mathrm{K}_{1}$ and $\mathrm{K}_{2}$ associated to tetrahedral and octahedral complexes have been deliberated employing the method recommended by Waldron [15]:

$$
\begin{array}{r}
\mathrm{K}_{1}=7.62 \cdot \mathrm{M}_{1} \cdot v_{1}^{2} \cdot 10^{-7} \mathrm{~N} / \mathrm{m} \\
\mathrm{K}_{2}=10.62 \cdot \mathrm{M}_{2} / 2 \cdot v_{2}^{2} \cdot 10^{-7} \mathrm{~N} / \mathrm{m}
\end{array}
$$

where $\mathrm{M}_{1}$ and $\mathrm{M}_{2}$ are the molecular weights calculated from estimated cationic distribution and $v_{1}$ and $v_{2}$ are the central frequencies at tetrahedral and octahedral sites. The estimated values of $\mathrm{K}_{1}$ and $\mathrm{K}_{2}$ are tabulated in Table 5.

The trend of bond lengths $\left(\mathrm{L}_{\mathrm{A}}, \mathrm{L}_{\mathrm{B}}\right)$ and force constant $\mathrm{K}_{1}$ and $\mathrm{K}_{2}$ as a function of zinc contents has been shown in Figures 4A and 4B.

It is clearly seen from Figure 4 that hopping length increases and lowers the force constant. This behavior may be attributed to the fact that if the substituent ion is of larger radius than that of replaced ion, then the distance between the magnetic ions increases and force constant decreases, which leads to reduction in the repulsive force and causes lowering the electrostatic energy. This implies lowering of the wave number and hence decreasing the force constant.

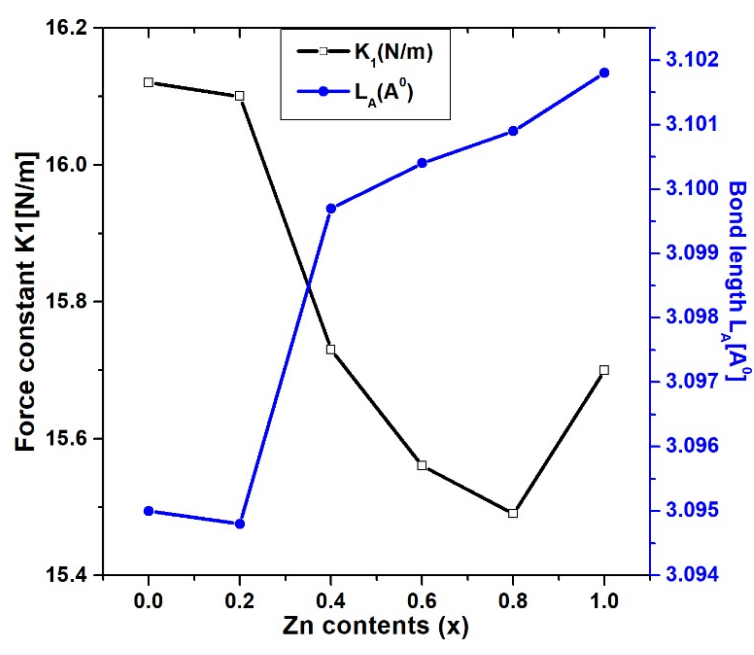

(A)

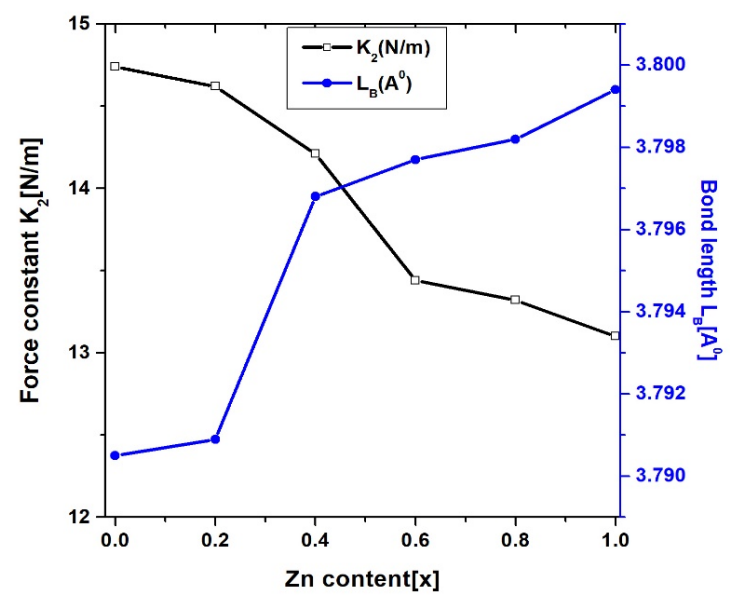

(B)

Fig. 4. (A, B) Variation of force constant and hopping length.

\subsubsection{Elastic properties}

The elastic properties are the amount of resistance against the stretching of lattice and are linked to the second derivative of interatomic potential. Elastic moduli have been calculated through structural data and IR data of currently investigated ferrite samples [16, 17]. These elastic moduli have calculated using the values of lattice constant "a", X-ray density "dx", pore fraction "f", and force constant "K". There is much more importance that can be attributed to elastic constants, for the reason that they illustrate the binding forces' nature and 
to recognize the thermal properties of materials. The often used elastic moduli are bulk modulus, young's modulus, rigidity modulus, and Poisson's ratio. Among all these elastic constants, young's modulus is of special concern due to its decisive factor for the most broadly employed core shapes, explicitly rods and rings [18]. It is generally known that average force constant $" \mathrm{k}_{\mathrm{av}}$ " is the product of stiffness constant " $\mathrm{C}_{11}=\mathrm{L}$ (longitudinal modulus)" and lattice parameters "a" i.e., $\left(\mathrm{k}_{\mathrm{av}}=\mathrm{C}_{11} \times\right.$ a) as $\mathrm{k}_{\mathrm{av}}=\left(\mathrm{k}_{1} \mathrm{k}_{2}\right) / 2$. The calculation of pore function has been done by relation $(f=1-d / \rho)$. The data analysis generated the given equation for the deviation of Poison's ratio as a pore function that is expressed as "(f) $=\rho=0.3241$ (1 1 1.043)". However, the Poison's ratio remains constant for varying compositions. The value is found to be 0.29 that lies in the range ( -1 to 0.5 ), which is the compliance with the isotropic elasticity theory. Thus, the following relations have been used to evaluate other elastic moduli of ferrite specimens [19] and their values have been written in Table 6 .

Stiffness constant:

$$
\left(\mathrm{C}_{12}\right)=\sigma \mathrm{C}_{11} / 1-\sigma
$$

Young's modulus:

$$
(E)=\left(C_{11}-C_{12}\right)\left(C_{11}+2 C_{12}\right) /\left(C_{11}+C_{12}\right)
$$

Rigidity modulus:

$$
(G)=E / 2(\sigma+1)
$$

Bulk modulus:

$$
(\mathrm{K})=1 / 3\left[\mathrm{C}_{11}+2 \mathrm{C}_{12}\right]=\mathrm{L}-(4 / 3) \mathrm{G}
$$

The stiffness constants $\left(\mathrm{C}_{11}\right.$ and $\left.\mathrm{C}_{12}\right)$ are showing the decreasing trend, as shown in Figure 5. It has been observed from the Figure 6 that elastic moduli are tending to decrease with addition of zinc contents that may be deduced in term of interatomic bonding. In the current system, the establishment of inter-atomic bonding of zinc replacement for cobalt and iron can be explained as follows: iron has $3 \mathrm{~d}^{5}$ and zinc ion has $4 \mathrm{~s}^{2}$ orbital configuration; these are substituted by zinc, which has $3 \mathrm{~d}^{10}$ configuration. Here $3 \mathrm{~d}^{5}$ is half filled while $4 \mathrm{~s}^{2}$
Table 6. Stiffness constant bulk modulus, young's modulus and rigidity modulus of $\mathrm{Co}_{1-\mathrm{x}} \mathrm{Zn}_{\mathrm{x}} \mathrm{Cr}_{0.5} \mathrm{Fe}_{1.5} \mathrm{O}_{4}$.

\begin{tabular}{llllll}
$\mathrm{x}$ & \multicolumn{2}{c}{ Stiffness constant $\begin{array}{l}\text { Young's } \\
\text { modulus } \\
\end{array}$} & & $\begin{array}{l}\text { Rigidity } \\
\text { modulus } \\
(\mathrm{E})\end{array}$ & $\begin{array}{l}\text { Bulk } \\
\text { modulus } \\
(\mathrm{K})\end{array}$ \\
\hline & $\mathrm{C}_{11}$ & $\mathrm{C}_{12}$ & & & \\
\hline \hline 0 & 1.840 & 0.881 & 5.11 & 3.10 & 3.46 \\
0.2 & 1.846 & 0.884 & 5.14 & 3.11 & 2.29 \\
0.4 & 1.792 & 0.852 & 4.86 & 2.94 & 2.08 \\
0.6 & 1.723 & 0.825 & 4.48 & 2.91 & 2.14 \\
0.8 & 1.722 & 0.825 & 4.47 & 2.71 & 1.88 \\
1.0 & 1.721 & 0.824 & 4.42 & 2.68 & 1.84 \\
\hline
\end{tabular}

is a completely filled orbit; so, they do not contribute to bond formation and are stable. On the other hand, $\mathrm{Zn}^{2+}$ has 10 electrons in d-shell, which is also completely filled and not able to form bonding with other cations or oxygen that cause decrease in the material strength.

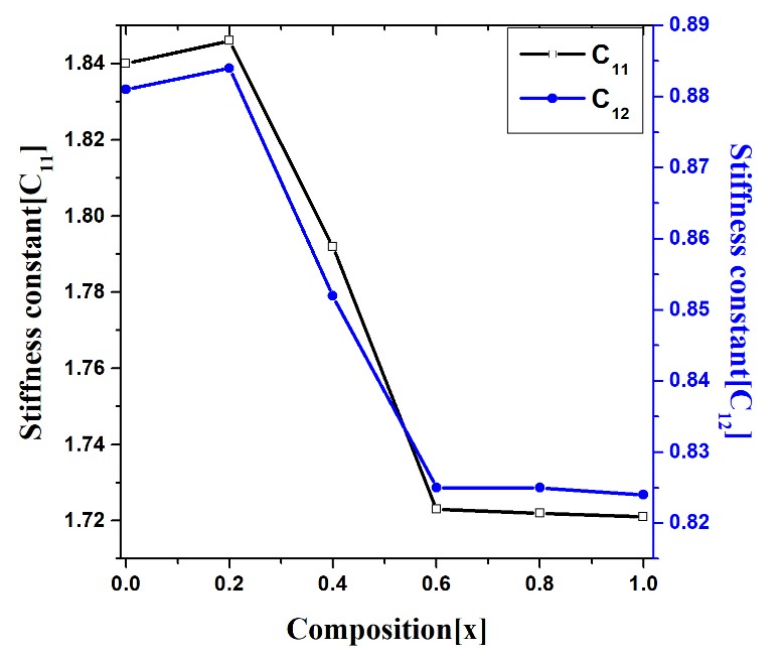

Fig. 5. Variation of stiffness constants with zinc contents of $\mathrm{Co}_{1-\mathrm{x}} \mathrm{Zn}_{\mathrm{x}} \mathrm{Cr}_{0.5} \mathrm{Fe}_{1.5} \mathrm{O}_{4}$.

\subsection{Scanning electron microscope}

The scanning electron microscope images of $\mathrm{Co}_{1-\mathrm{x}} \mathrm{Zn}_{\mathrm{x}} \mathrm{Cr}_{0.5} \mathrm{Fe}_{1.5} \mathrm{O}_{4}$ ferrites are shown in Figure 7. All the images confirm that grains are of cubical shape and the geometric morphology shows 


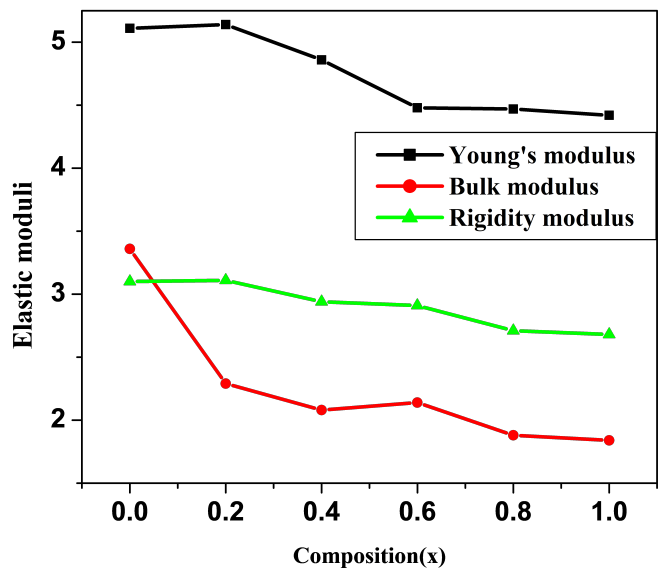

Fig. 6. Variation of elastic moduli with dopant concentration.

that particles are agglomerated and moderately distributed. It is evident from the results obtained through the scanning electron microscope (SEM) that the prepared materials are affected by the zinc substitution. The material without doping shows fine grains and homogenous microstructure. The dense agglomeration and the mixture of cuboid and elongated particles have been seen with the doping of zinc ions. Furthermore, the agglomeration of particles can be attributed to high calcination temperature because of emerging forces such as capillary, Van-der walls, and electrostatic forces, which generate the mutual interaction among particles [20]. It can be seen from figure that agglomeration is enhancing with increasing zinc ion content. In addition, the bigger ionic radius of zinc ion could result in an increase in grain size, with reside on the grain boundary of cations' vacancies in lattice [21]. The average grain size has been estimated from micrograph by linear intercept method and listed in Table 1. It is observed that grain size decreases in the range of 142-96 nm with increasing the zinc contents, which may be due to lattice strain. The comparable observation has been perceived from the results of XRD [22].

\subsection{Vibrating sample magnetometer}

The hysteresis loops that trace the changes in magnetization as a function of applied field " $\mathrm{H}$ " for $\mathrm{Zn}_{\mathrm{x}} \mathrm{Co}_{1-\mathrm{x}} \mathrm{Cr}_{0.5} \mathrm{Fe}_{1.5} \mathrm{O}_{4}$ ferrites are measured at room temperature and are shown in Figure 8. Different parameters such as saturation magnetization, remnant magnetization, squareness, observed, and calculated magnetic moment are extracted from Figure 8 and their values are listed in Table 7.

It is observed from the above table that the substitutions of zinc ions are decreasing the saturation magnetization $\left(\mathrm{M}_{\mathrm{S}}\right)$ of the material. This trend may be explained on the basis of "Neel's sub-lattice model". According to this model, when the nonmagnetic zinc ions $\left(0 \mu_{\mathrm{B}}\right)$ replace the cobalt ions $\left(3 \mu_{\mathrm{B}}\right)$ at $\mathrm{B}$-site, the magnetic moment reduces at octahedral site and weakens the A-B interaction. Moreover, the zinc ions with larger ionic radius substitute the cobalt ions on octahedral site; so, the distance between ions increases at this site, which leads to decrease in the B-B interaction. At the same time, some of the iron ions are also forcefully shifted toward the A-site and strengthen the A-A interaction; as a result, there occurs a net decrement in magnetic moment; consequently, the saturation magnetization decreases.

The value of $M_{r} / M_{s}$ reduces with enhancement of the zinc contents, which shows a significant fraction of supermagnetic particles. It has been observed from Table 7 that the values of coercivity are found to decrease with zinc contents. The decline in magnetic property in prepared materials may be due to incomplete replacement of zinc ions, due to existence of super magnetic particles or due to size effect. The value of coercivity has been found maximum at lowest concentration of zinc, but on increasing the zinc ions, the value of coercivity approaches close to zero; thus, at room temperature, these materials show superparamagnetic behavior. These properties make these kind of materials suitable for extensive engineering applications, such as magnetic refrigeration systems and bio separators $[23,24]$.

The observed value of magnetic moment per formula unit (Bohr magneton) has been deliberated by relation $[25,26]$ :

$$
\mu_{\mathrm{B}}(\mathrm{obs})=\left(\text { Mol.wt } \cdot \mathrm{M}_{\mathrm{S}}\right) / 5585
$$



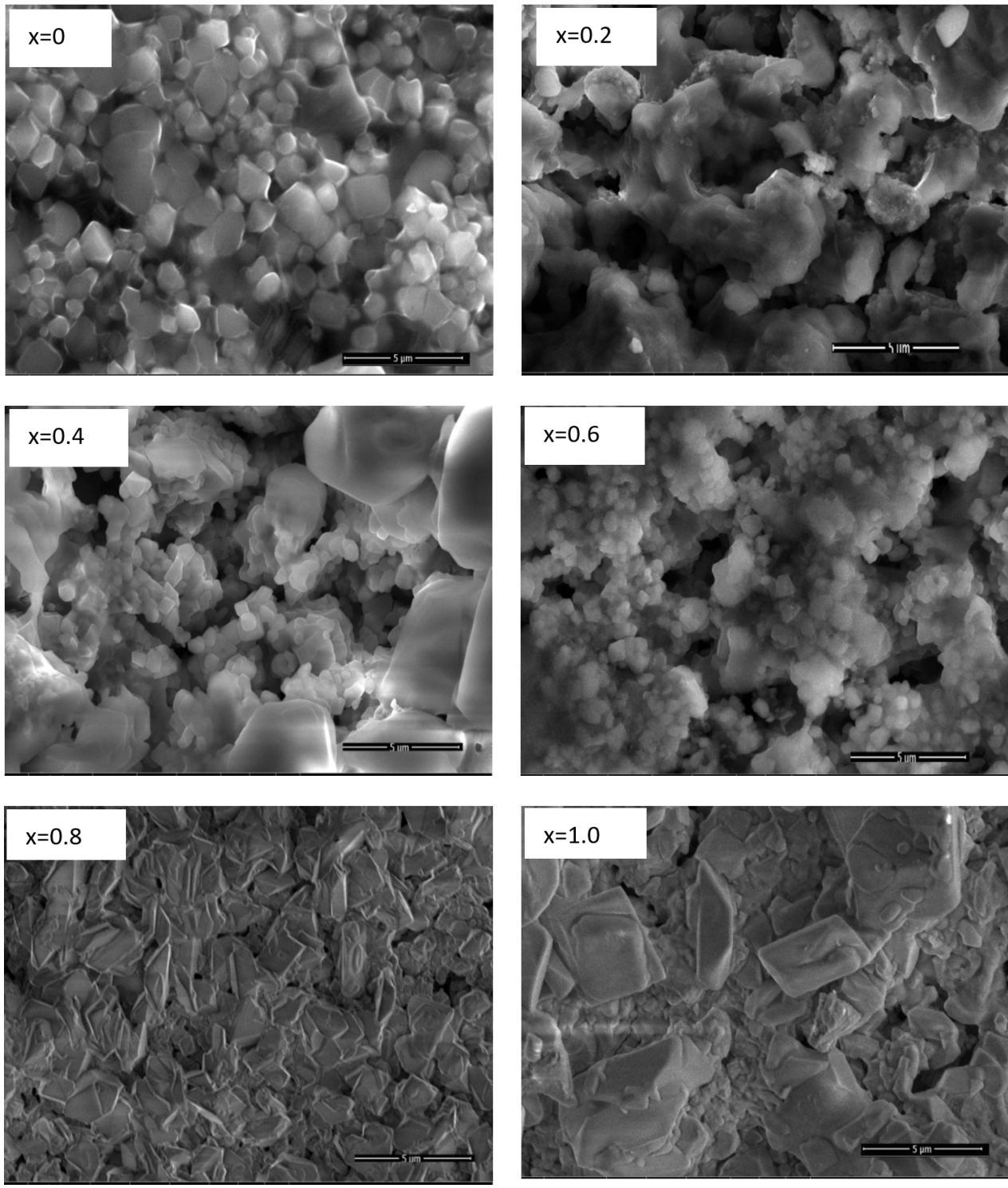

Fig. 7. Scanning electron microscopy at the resolution of $5 \mu \mathrm{m}$.

Table 7. Magnetization data for $\mathrm{Zn}_{\mathrm{x}} \mathrm{Co}_{1-\mathrm{x}} \mathrm{Cr}_{0.5} \mathrm{Fe}_{2} \mathrm{O}_{4}$.

\begin{tabular}{lllllll}
\hline $\begin{array}{l}\text { Zn contents } \\
(\mathrm{x})\end{array}$ & $\begin{array}{l}\mathrm{M}_{\mathrm{S}} \\
(\mathrm{emu} / \mathrm{g})\end{array}$ & $\begin{array}{l}\mathrm{M}_{\mathrm{r}} \\
(\mathrm{emu} / \mathrm{g}) \times 10^{-2}\end{array}$ & $\mathrm{M}_{\mathrm{r}} / \mathrm{M}_{\mathrm{s}} \times 10^{-2}$ & $\begin{array}{l}\mu_{B}(\mathrm{obs}) \\
\text { magneton } \times 10^{-2}\end{array}$ & $\begin{array}{l}\text { bohr } \mu_{B} \text { (cal) bohr Coercivity } \\
\text { magneton }\end{array}$ & $\mathrm{kO}_{\mathrm{e}}$ \\
\hline \hline 0 & 4.366 & 3.88 & 0.88 & 3.056 & 3.0 & 102.30 \\
0.2 & 3.370 & 3.80 & 1.12 & 2.461 & 2.7 & 37.27 \\
0.4 & 1.464 & 2.57 & 1.75 & 1.114 & 2.0 & 2.781 \\
0.6 & 0.4317 & 2.24 & 5.19 & 0.342 & 1.3 & 0.821 \\
0.8 & 0.4249 & 0.493 & 1.16 & 0.349 & 0.6 & 0.404 \\
1.0 & 0.2930 & 0.387 & 1.32 & 0.250 & 0.5 & 0.412 \\
\hline
\end{tabular}




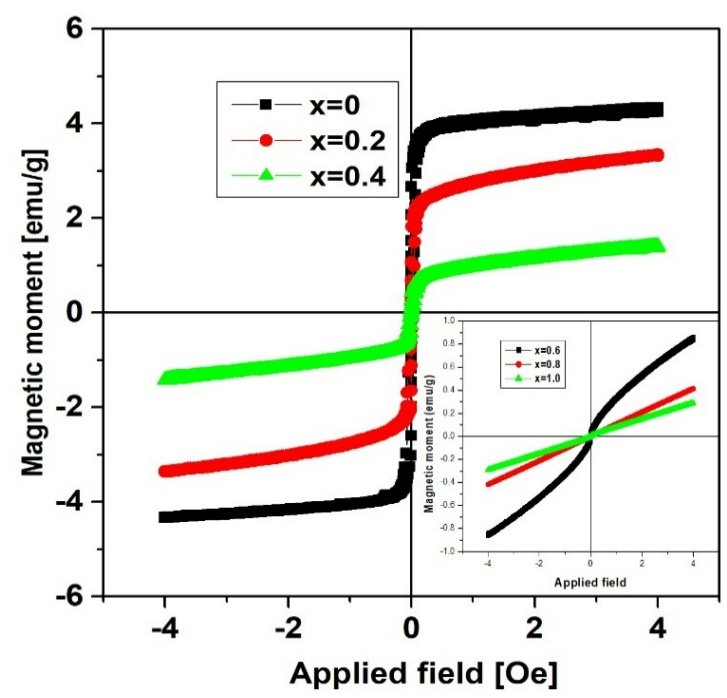

Fig. 8. Hysteresis loops of $\mathrm{Zn}_{\mathrm{x}} \mathrm{Co}_{1-\mathrm{x}} \mathrm{Cr}_{0.5} \mathrm{Fe}_{1.5} \mathrm{O}_{4}$.

Similarly, the calculated magnetic moment per formula unit $\left(\mathrm{M}_{\mathrm{Cal}}\right)$ has been deliberated using the formula as per [27]:

$$
\mu_{\mathrm{B}}(\mathrm{cal})=\mathrm{M}_{\mathrm{B}}(\mathrm{x})-\mathrm{M}_{\mathrm{A}}(\mathrm{x})
$$

where $\mathrm{M}_{\mathrm{A}}$ is the magnetic moment of sublattice $A$, and $M_{B}$ is the magnetic moment of sublattice $\mathrm{B}$, and their values has been intended from cationic distribution.

For instance at $(\mathrm{x}=0)$,

$$
\begin{aligned}
\mu_{\mathrm{B}}(\mathrm{cal}) & =\left(\mathrm{Co}_{0.75} \mathrm{Cr}_{0.5} \mathrm{Fe}_{0.75}\right)-\left(\mathrm{Co}_{0.25} \mathrm{Fe}_{0.75}\right) \\
& =(0.75 \cdot 3+0.5 \cdot 3+0.75 \cdot 5) \\
& -(0.3 \cdot 3+0.75 \cdot 5) \\
& =3.0 \mu_{\mathrm{B}} / \text { f.u }
\end{aligned}
$$

Similarly, calculated magnetic moment per formula unit at $(\mathrm{x}=1)$

$$
\begin{aligned}
\mathrm{M}_{\mathrm{Cal}} & =\left(\mathrm{Zn}_{0.99} \mathrm{Cr}_{0.42} \mathrm{Fe}_{0.59}\right)-\left(\mathrm{Zn}_{0.0} \mathrm{Cr}_{0.08} \mathrm{Fe}_{0.91}\right) \\
& =(0.99 \cdot 0+0.42 \cdot 3+0.59 \cdot 5) \\
& -(0.01 \cdot 0+0.08 \cdot 3+0.91 \cdot 5) \\
& =0.5 \mu_{\mathrm{B}} / \mathrm{f} . \mathrm{u}
\end{aligned}
$$

The comparison of calculated and observed magnetic moment has been shown in Figure 9. It has been perceived from the said figure that both calculated and observed values of magnetic moment per formula unit confirm the decreasing behavior, which results due to substitution of nonmagnetic Zn with Co.

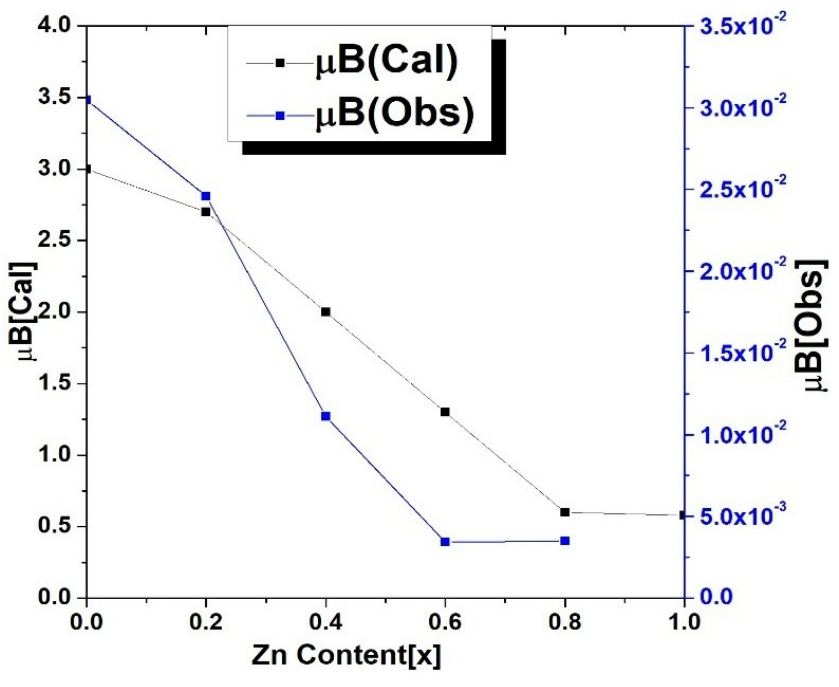

Fig. 9. Observed and calculated magnetic moment per formula unit.

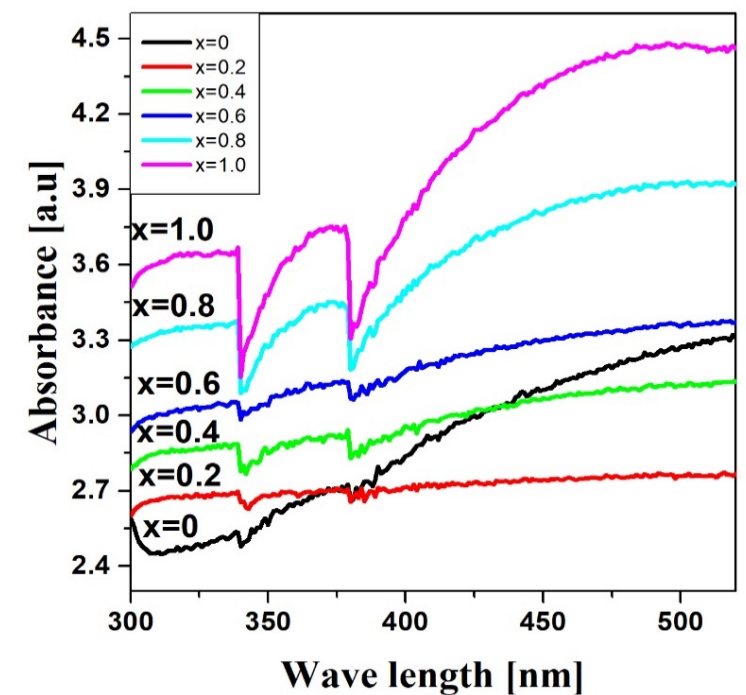

Fig. 10. Absorbance spectra of $\mathrm{Co}_{1-\mathrm{x}} \mathrm{Zn}_{\mathrm{x}} \mathrm{Cr}_{0.5} \mathrm{Fe}_{1.5} \mathrm{O}_{4}$ as a function of $\mathrm{Zn}$ contents.

These results are in good agreement with references in the literature that pertain to the materials obtained by solid stat reaction method.

\subsection{UV-Visible spectral analysis}

The absorption spectra of $\mathrm{Co}_{1-\mathrm{x}} \mathrm{Zn}_{\mathrm{x}} \mathrm{Cr}_{0.5} \mathrm{Fe}_{1.5} \mathrm{O}_{4} \quad(\mathrm{x}=0, \quad 0.2, \quad 0.4, \quad 0.6$, $0.8,1.0)$ samples that have been recorded in the wavelength range $200-800 \mathrm{~nm}$ by ultraviolet Visible Spectroscopy (UV-VIS) spectrometer are shown in Figure 10. 

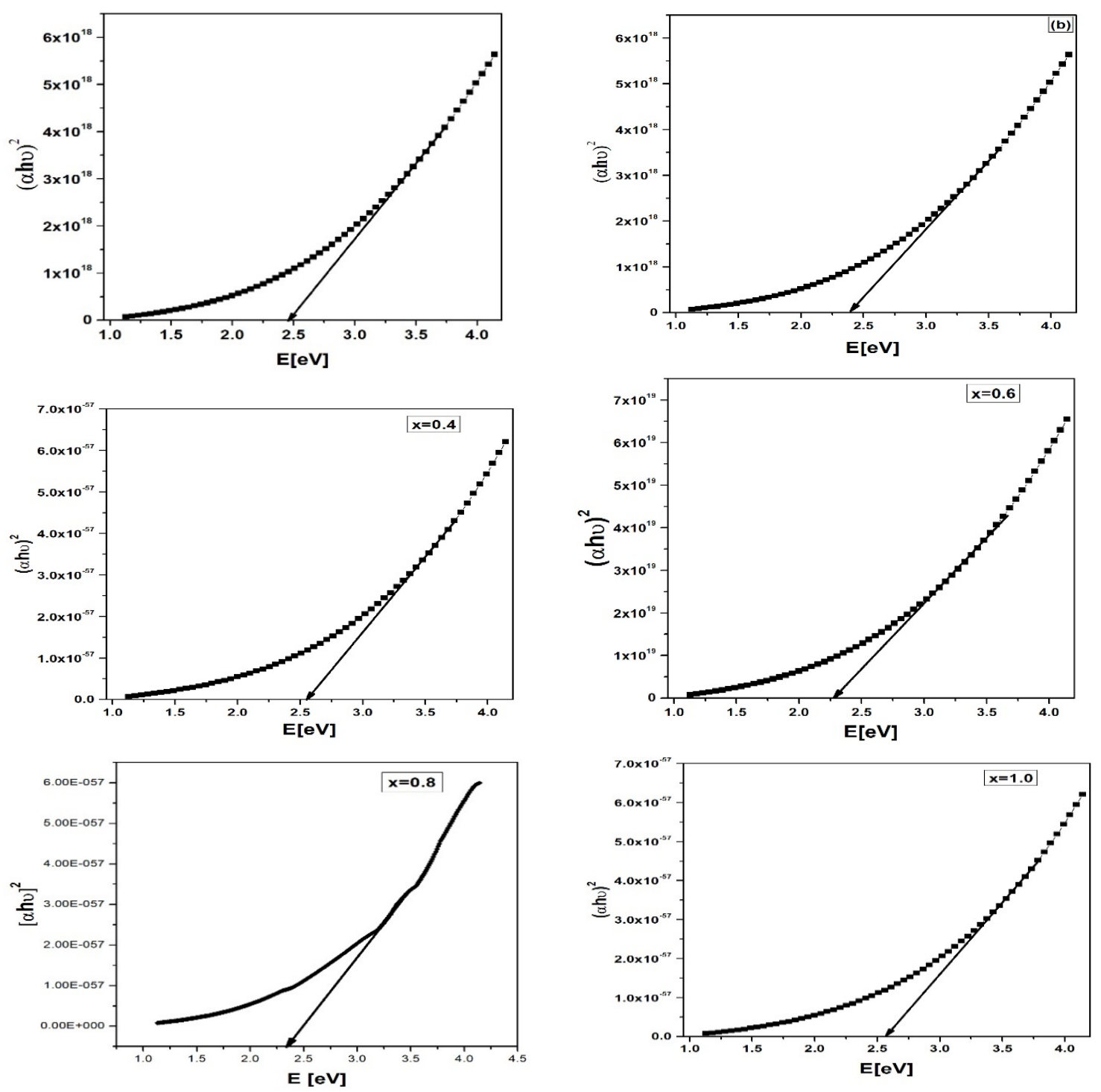

Fig. 11. UV-Visible spectroscopy for $\mathrm{Co}_{1-\mathrm{x}} \mathrm{Zn}_{\mathrm{x}} \mathrm{Cr}_{0.5} \mathrm{Fe}_{1.5} \mathrm{O}_{4}$.

The optical band gap energy is calculated using the Tauc relation [28]:

$$
\alpha h v=A(h v-E g)^{n}
$$

where " $h$ " is the photon energy, A is constant which depends on transition probability, and " $n$ " depends on the transition nature; theoretically, it is 2 and $1 / 2$ for indirect and direct allowed transition. The investigation of band gap energy has been done by plotting the graph between $(h)^{2}$ and $E_{g}$, and the band gap energy estimation has been done by extrapolating the linear part of the curve that is shown in Figure 11.The values of $E_{g}$ have been listed in Table 1.

The relation of band gap energy and crystallite size as a function of zinc concentration is shown in Figure 12. It has been professed from the figure that the band energy increases with increasing the zinc concentration; that may be due to the smaller size of grains. As the grains becomes finer and approaches to nano scale, where the particles made up of finite number of atoms, then the electron - 
hole pairs become close to each other; so, the electrostatic coulomb force is no more neglected and provides the higher kinetic energy. The wider band gap means that higher energy is required for the excitation of electrons from the valance band to the conduction band. The increase in band gap is also because of the reason that as the size of grains decreases, the number of atoms turns to be finite and the bandwidth starts to narrow due to overlapping of energy levels or orbitals. The increase in band gap is observed by the blue shift in the spectra, as shown in Figure 10.

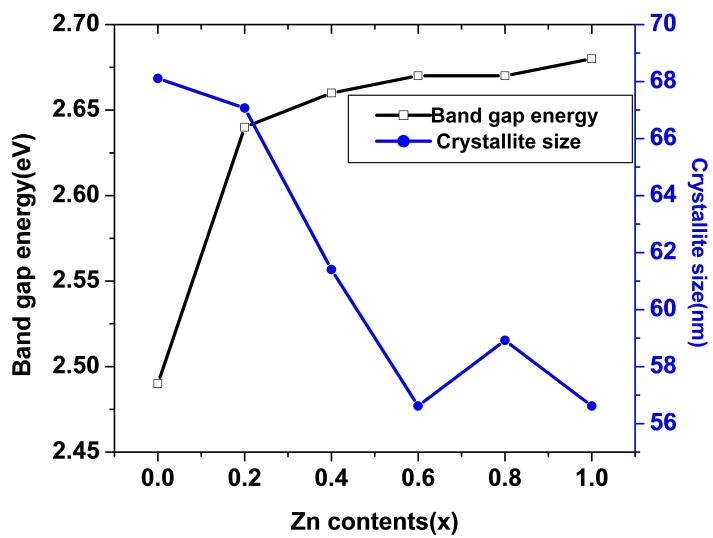

Fig. 12. Variation of crystallite size with optical band gap energy.

\section{Conclusions}

Solid state reaction method has been used to fabricate the $\mathrm{Co}_{1-\mathrm{x}} \mathrm{Zn}_{\mathrm{x}} \mathrm{Cr}_{0.5} \mathrm{Fe}_{1.5} \mathrm{O}_{4}$ ferrite at sintering temperature $1,100{ }^{\circ} \mathrm{C}$. The formation of spinel ferrites have been confirmed by XRD and FTIR analysis. The lattice parameters are found to increase with increasing the zinc content, which is due to larger ionic radii of zinc than cobalt ion. It has been revealed from the results of magnetic properties that the saturation magnetization and remnant magnetization both decrease with the enhancement of $\mathrm{Zn}^{2+}$ concentration, which is due to replacement of non-magnetic $\mathrm{Zn}^{2+}$ ions with $\mathrm{Co}^{2+}$ ions and migration of $\mathrm{Fe}^{2+}$ ions from octahedral site to tetrahedral site. The hysteresis loop shows that the coercivity value is extremely low; so, the material goes toward the softness. This is because higher concentration of zinc material behaves as a paramagnetic material. The SEM images show the fine grains.

\section{References}

[1] Xia Y, Yang P, Sun Y, Wu Y, Mayers B, Gates B, et al. One-dimensional nanostructures: synthesis, characterization, and applications. Adv Mater. 2003;15(5):35389.

[2] Ding J, Jain S, Adeyeye A. Static and dynamic properties of one-dimensional linear chain of nanomagnets. J Appl Phys. 2011;109(7):07D301.

[3] Rani R, Sharma S, Pirota K, Knobel M, Thakur S, Singh M. Effect of zinc concentration on the magnetic properties of cobalt-zinc nanoferrite. Ceram Int. 2012;38(3):2389-94.

[4] Cullity B. Element of X-ray diffraction, AddisonWesley reading. MA Google Scholar, 1978.

[5] Gabal M, Ahmed M. Structural, electrical and magnetic properties of copper-cadmium ferrites prepared from metal oxalates. J Mater Sci. 2005;40(2):387-98.

[6] Sharma R, Singhal S. Structural, magnetic and electrical properties of zinc doped nickel ferrite and their application in photo catalytic degradation of methylene blue. Phys B Condens Matter. 2013;414:83-90.

[7] Salah L, Moustafa A, Farag IA. Structural characteristics and electrical properties of copper doped manganese ferrite. Ceram Int. 2012;38(7):5605-11.

[8] Shaikh P, Kambale R, Rao A, Kolekar Y. Studies on structural and electrical properties of Co 1- x Ni x Fe 1.9 Mn 0.1 O 4 ferrite. J Alloys Compd. 2009;482(1):27682.

[9] Humbe AV, Kounsalye JS, Shisode MV, Jadhav K. Rietveld refinement, morphology and superparamagnetism of nanocrystalline Ni0. 70- xCuxZn0. 30Fe2O4 spinel ferrite. Ceram Int. 2018;44(5):5466-72.

[10] Tatarchuk T, Bououdina M, Paliychuk N, Yaremiy I, Moklyak V. Structural characterization and antistructure modeling of cobalt-substituted zinc ferrites. J Alloys Compd. 2017;694:777-91.

[11] Kadam R, Birajdar A, Alone ST, Shirsath SE. Fabrication of $\mathrm{Co}$. $5 \mathrm{Ni}$. $5 \mathrm{CrxFe} 2-\mathrm{xO} 4$ materials via sol-gel method and their characterizations. J Magn Magn Mater. 2013;327:167-71.

[12] Robertson J. Elements of X-ray diffraction by BD Cullity. International Union of Crystallography; 1979.

[13] Levine B. d-Electron effects on bond susceptibilities and ionicities. Phys Rev B. 1973;7(6):2591.

[14] Groń T. Influence of vacancies and mixed valence on the transport processes in solid solutions with the spinel structure. Philos Mag B. 1994;70(1):121-32.

[15] Pradeep A, Priyadharsini P, Chandrasekaran G. Solgel route of synthesis of nanoparticles of MgFe 204 and XRD, FTIR and VSM study. J Mag Mag Mater. 
2008;320(21):2774-9.

[16] Modi K, Shah S, Pujara N, Pathak T, Vasoya N, Jhala I. Infrared spectral evolution, elastic, optical and thermodynamic properties study on mechanically milled Ni0. 5Zn0. 5Fe2O4 spinel ferrite. J Mol Struct. 2013;1049:250-62.

[17] Pathak T, Buch J, Trivedi U, Joshi H, Modi K. Infrared spectroscopy and elastic properties of nanocrystalline $\mathrm{Mg}-\mathrm{Mn}$ ferrites prepared by co-precipitation technique. J Nanosci Nanotechnol. 2008;8(8):4181-7.

[18] Modi K, Gajera J, Pandya M, Vora G, Joshi H. Far-infrared spectral studies of magnesium and aluminum co-substituted lithium ferrites. Pramana. 2004;62(5):1173-80.

[19] Patil V, Shirsath SE, More S, Shukla S, Jadhav K. Effect of zinc substitution on structural and elastic properties of cobalt ferrite. J Alloys Compd. 2009;488(1):199-203.

[20] Sanpo N, Wen C, Berndt CC, Wang J. Antibacterial properties of spinel ferrite nanoparticles. In: Microbial pathogens and strategies for combating them: science, technology and education. Spain: Formatex Research Centre; 2013. pp. 239-50.

[21] Ali AI, Ahmed MA, Okasha N, Hammam M, Son JY. Effect of the La3+ ions substitution on the magnetic properties of spinal Li-Zn-ferrites at low temperature. J Mater Res Technol. 2013;2(4):356-61.

[22] Waldron R. Infrared spectra of ferrites. Physical Review. 1955;99(6):1727.

[23] Sun S, Zeng H, Robinson DB, Raoux S, Rice PM, Wang SX, et al. Monodisperse $\mathrm{mfe} 2 \mathrm{o} 4(\mathrm{~m}=\mathrm{fe}, \mathrm{co}, \mathrm{mn})$ nanoparticles. J Am Chem Soc. 2004;126(1):273-9.

[24] Tanaka K, Nakashima S, Fujita K, Hirao K. High magnetization and the Faraday effect for ferrimagnetic zinc ferrite thin film. J Phys Condens Matter. 2003;15(30):L469.

[25] Murumkar V, Modi K, Jadhav K, Bichile G, Kulkarni R. Magnetic and electrical properties of aluminium and chromium co-substituted yttrium iron garnets. Mater Lett. 1997;32(4):281-5.

[26] Polezhaeva O, Yaroshinskaya N, Ivanov V. Synthesis of nanosized ceria with controlled particle sizes and bandgap widths. Russ J Inorg Chem. 2007;52(8):11848.

[27] Gilleo M. Superexchange interaction in ferrimagnetic garnets and spinels which contain randomly incomplete linkages. J Phys Chem Solids. 1960;13(1-2):33-9.

[28] Anjum S, Rafique MS, Khaleeq-ur-Rahman M, Siraj K, Usman A, Hussain S, et al. Investigation of induced parallel magnetic anisotropy at low deposition temperature in Ba-hexaferrites thin films. J Magn Magn Mater. 2012;324(5):711-6.

[29] R. Arulmurugan, B. Jeyadevan, G. Vaidyanathan and S. Sendhilnathan, "Effect of Zinc Substitution on Co$\mathrm{Zn}$ and Mn-Zn Ferrite Nanoparticles Prepared by CoPrecipitation," Journal of Magnetism and Magnetic Materials, Vol. 288, 2005, pp. 470-477.

Received 15-04-2021

Accepted 16-04-2021 